International Journal of MCH and AIDS (2019), Volume 8, Issue I, I I- I8

\begin{tabular}{ll}
\hline & INTERNATIONAL JOURNAL \\
& of MCH and AIDS \\
& ISSN 2 I6I-864X (Online) \\
IJMA & ISSN 216I-8674 (Print) \\
& DOI: I0.2 I I06/ijma.264 \\
\hline
\end{tabular}

\title{
ORIGINALARTICLE
}

\section{Decision Making Autonomy and Maternal Healthcare Utilization among Nigerian Women}

Phillips Edomwonyi Obasohan, MBA, MEd, MSc;' Paul Gana, MSc; ${ }^{2}$ Mahmud A. Mustapha, MSc; ${ }^{2}$ Ahmed Egbako Umar, PhD; ${ }^{2}$ Audu Makada, MSc; ${ }^{2}$ Dorcas Nike Obasohan, BSc $^{3}$

'Department of Liberal Studies, College of Administrative and Business Studies, Niger State Polytechnic, Bida Campus, Niger State, Nigeria, 2,Department of Mathematics and Statistics, College of Science and Technology, Niger State Polytechnic, Zungeru Campus, Niger State, Nigeria, ${ }^{3}$ Department of Nursing Services, Comprehensive Health Centre/Federal Medical Centre, Zungeru, Niger State, Nigeria

Corresponding author email: philiobas@yahoo.com

ABSTRACT

Background and Objectives: Low assess to ante-natal care (ANC) services continue to pose a major public health challenge leading to high maternal mortality rates in developing countries. Non-utilization of ANC services among about a quarter of Nigerian women of reproductive age remains a major concern in the actualization of Sustainable Development Goals. Considering the complexity of healthcare utilization in Nigeria, the relationship between a particular health care utilization pattern and women autonomy has not been fully examined. This study examines the patterns of women autonomy and their relationships with ANC utilization in Nigeria.

Methods: This was a cross-sectional analysis of the 2013 nationally representative data from the Nigerian Demographic and Health Survey (NDHS). Factor analysis/score were used to construct women autonomy index, while chi-square and logistic regression were used to establish the relationships between the response and exposure variables.

Results: There is a strong relationship between women decision making autonomy status and ANC services among Nigeria women. The odds of utilizing ANC services among women with more decision making autonomy were significantly 3.79 higher than among women with low decision-making autonomy. The use of ANC increases as age, education and wealth status of respondents increase.

Conclusions and Global Health Implications: These results indicate that women autonomy is undoubtedly a major determinant of ANC utilization in Nigeria.

Key words:Autonomy, Antenatal Care, Logistic Regression Analysis; Factor analysis

Copyright (C) 2019 Obasohan et al. This is an open-access article distributed under the terms of the Creative Commons Attribution License, which permits unrestricted use, distribution, and reproduction in any medium, provided the original work is properly cited.affect economic and health promotion. 


\section{Introduction}

\section{I.I Background of the study}

Poor maternal health care utilization is of great concern in developing countries leading to high maternal and child mortality. Globally, maternal mortality is very high with about 830 women dying every day from pregnancy or childbirth related.' In 2010, World Health Organization (WHO) reported that 358,000 maternal mortalities occurred globally, with more than 354,000 occurring in developing countries and about 200,000 deaths in sub-Saharan African countries. ${ }^{2}$ This has, however, dropped in 2015 to 303,000 women death globally. ${ }^{3,1}$

Studies have established that maternal mortality and morbidity are inversely proportional to health care services utilization. That is, when healthcare service utilization is low, this will translate into high maternal and child mortalities. Also, where reproductive healthcare utilization is high, maternal and child mortalities would be low. ${ }^{4}$ One of the most common indicators of a woman's health and reproductive behavior is the state of her antenatal care utilization rate. $^{5}$

The prevalence of non-utilization of healthcare services among several Nigerian women of reproductive age remains a major concern to all stakeholders in the actualization of Sustainable Development Goals (SDGs) by year 2030. It's been reported that more than $33 \%$ of Nigerian pregnant women do not use antenatal care (ANC) service during pregnancy. ${ }^{4}$ For instance, the WHO's World Health Statistics reported that in 2015 only $61 \%$ of Nigerian pregnant women had attended ANC at least once during their pregnancy period and only $51 \%$ met the WHO standard of a minimum of 4 visits. $^{6}$

Women autonomy as collected in the Nigeria Demographic and Health Survey (NDHS) is defined as the extent to which women are independent on finances, level of participation in family decision making on matters pertaining to her health and that of the household, and freedom to visit outside of her matrimonial home without having to obtain permission. ${ }^{7}$ Recent studies have reported mixed conclusions on the relationship between women's autonomy and reproductive healthcare utilization. In some Asian countries, studies found association between women autonomy and use of reproductive healthcare services. ${ }^{8,9}$ On the other hand, ${ }^{10}$ one Nepal study concluded that women's participation in decision making was not associated with the use of prenatal and postnatal care, while another in another study, Deo et al "' found that autonomy is associated with ANC services in Eastern Nepal. However, some studies in Nigeria and sub-Saharan Africa (SSA) found that women autonomy is associated with maternal healthcare services. ${ }^{12,13,14}$

There are a number of other studies that have investigated the factors responsible for poor maternal healthcare services utilization and many of these studies used the classical regression analysis. For instance, a study conducted by Bamiwuye et al ${ }^{15}$ used composite score to obtain an overall index for autonomy by adding the dichotomous variables in all the situations for which data were available to have a minimum score of ' 0 ' and maximum of ' 4 ' with higher scores meaning 'more autonomy'. These were further dichotomized into ' 0 ' (less autonomy) and 'I' (more autonomy). However, to our knowledge, studies adopting factor analysis are not available. Factor analysis (or principal component factor) is a more robust method that captures the totality of the constituents including their interactions by examining the correlation matrix to capture the underlying factors that explain substantial amount of variations.

\section{I.2 Aims of the study}

The aim of this study therefore was to determine the patterns of women decision making autonomy and establish how it relates with maternal healthcare utilization in Nigeria using factor analysis, factor score, and logistic regression with and without adjusting for confounding variables.

\section{Methods}

The 2013 NDHS datasets was used for this analysis. NDHS is a nationally representative survey carried out for Nigeria by MEASURE DHS in collaboration with National Population Commission (NPC). ${ }^{7}$ 
The survey has comparable questions on women decision making autonomy and number of ANC visits. For women decision making autonomy, data in 2013 NDHS was collected on the bases of their participation in three dimensions on issues concerning (i) their own health care, (ii) making major household purchases, and (iii) visits to family or relatives without having to take permission. ${ }^{8}$ For ANC visits, data showed a range of visits from 0 to 36 times during the period of pregnancy with at least 4 visits considered for this study as having attended adequate ANC visits in accordance with WHO standard as at the time of the survey without prejudice to the recent $\mathrm{WHO}$ recommendation of a minimum of 8 visits. ${ }^{16,17}$ In addition, for this study, weights were constructed to correct for imbalance in sampling to ensure national representativeness resulting in a weighted sample of 27,829 women.

\section{I Study variables}

The outcome variable (Dependent Variable) is the number of times a woman attended ANC during the last pregnancy. This was categorized as ' 0 ' if she attended less than 4 times and ' $I$ ' if she attended at least 4 times. The principal independent variable (predictor variable) is the decision making status of the woman and was dichotomized as ' 0 ' representing 'low autonomy' and ' $I$ ' representing 'more autonomy'. Other confounding variables of interest examined include: age of respondent and age at $\mathrm{I}^{\text {st }}$ marriage, where classified in group as (15-24, 25-34 and 35+), others were marital status (never in union, formerly in union and currently in union); number of children ever born $(0-4,5+)$ and number children living $(0,1-2,3-4,5+)$, the household wealth status classified as 'low' or 'high', education status (no education, primary education and secondary education and above); place of residence (whether rural or urban); and region (North East, North West, North Central, South East, South West and South South).

\subsection{Statistical analysis}

Four levels of analyses procedures were adopted:

- Level one, at the univariate level, percentage frequency distribution of the study sample was used to show the distribution of respondents by their characteristics and ANC prevalence.

- Level two, to construct autonomy status, factor analysis/score were used while considering the three dimensions as dichotomous where ' $I$ ' means participating and ' 0 ' not participating. In view of this, we extracted the commonalities, the proportion of the variance explained, the loading of the variables on the factor, the factor score coefficients for each variable and the test of model appropriateness. ${ }^{18}$

- Level three, to establish the relationship of the independent variable (decision making autonomy index derived from factor analysis) with maternal health care utilization, we used chi square at $5 \%$ level of significance.

- Level four, logistic regression analysis was used to establish the likelihood effects of principal variable (unadjusted) and (adjusted for confounding factors) with ANC visits. Statal4SE was used for the computation. ${ }^{19}$

\subsection{Ethical approval}

Being a secondary data survey, the ethical permission to use the data for this study was obtained from Opinion Research Corporation (ORC) Macro International, Incorporated, Calverton, USA with its approval for survey already approved by Ethics Committee of ORC Macro Inc. and by the National Ethics Committee of Federal Ministry of Health, Nigeria. ${ }^{7}$

\section{Results}

\section{I. Factor analysis of autonomy status}

Using principal component factor of factor analysis, one factor was extracted accounting for $81 \%$ of the total variance. The Bartlett test of sphericity for decision making autonomy among Nigerian women was highly significant $(p<0.000)$ with chi-square of 44793 indicating homogeneity of variance by the decision making patterns.

The following equation was used to construct the autonomy score (AS):

$$
\mathrm{AS}=0.44 \mathrm{~F}+0.36 \mathrm{H}+0.30 \mathrm{~V}
$$

The resulting values which lie between 0 and I.I were rescaled and multiplied by 100 to give values 
between zero and 100. This was finally dichotomized into 50/50, 5,15 resulting into autonomy index used for the analysis classified as ' 0 ' low autonomy and as ' $\mathrm{l}$ ' more autonomy as presented below in Table la and Ib.

This puts the prevalence rate of low decision making autonomy among Nigerian women to $60 \%$ (table Ib).

\subsection{Distribution of participant's characteristics}

As show in table 2, the mean age of respondents was 28.86 years with standard deviation of 9.68 years. More than $90 \%$ of women with age at first marriage between 15 and 24 years participated in the survey. The prevalence of ANC visits meeting the WHO standard (4 times and above during pregnancy) among Nigerian women was slightly above $52 \%$. Over I I,000 of the women in the survey do not have any living child and $22 \%$ have more than 4 children. The table also reveals that about three quarters of the women participants are currently in union with about $5 \%$ formerly in union, but now no longer in union. An equal number of women who have never had a child also had five or more children.

Table 3 shows that ANC visits at the $\mathrm{WHO}$ standard varied with a number of the background variables of participants. Other variables that were significantly associated with ANC include: age in

Table Ia: Results of the constructing the autonomy index

\begin{tabular}{lccc}
\hline Decision on & $\begin{array}{c}\text { Factor } \\
\text { loading }\end{array}$ & $\begin{array}{c}\text { Factor } \\
\text { score }\end{array}$ & Communalities \\
\hline Finance (F) & 0.92 & 0,44 & 0.84 \\
\hline Health (H) & 0.90 & 0.36 & 0.81 \\
\hline Visits (V) & 0.88 & 0.30 & 0.78 \\
\hline$\%$ of Variance 8I & & \\
\hline KMO 0.736 & & \\
\hline $\begin{array}{l}\text { Bartlett Test of Sphericity: } \\
* \text { P-Value=0.000 Chi-Sq. 44793 }\end{array}$ & & \\
\hline Number of Observation. 27274 & & \\
\hline
\end{tabular}

Table I b: Level of autonomy

\begin{tabular}{lcc}
\hline Description & $\mathbf{N}$ & $\%$ \\
\hline Low autonomy & 16,568 & 59.53 \\
\hline More autonomy & I I,262 & 40.47 \\
\hline
\end{tabular}

group, number of children ever born, household wealth index, number of children living, level of educational attainment, etc. The proportion of women whose age at first marriage was $35+$ years (86\%) that met WHO ANC standard was more than those for any other age group. ANC utilization was significantly lower among the rural women (38.9\%) than among the urban women (77.6\%).ANC utilization significantly increased among women with higher education from 2699 with no formal education to 5377 for those who have completed secondary education and above.

\subsection{Logistic regression analysis}

\subsection{Unadjusted odds ratio (UOR)}

Table 4 shows the logistic regression odds ratio of individual estimates (unadjusted) of the ANC utilization among Nigerian women by the principal variable (decision making autonomy). The odds of ANC utilization increase by a woman's level of decision making autonomy. The unadjusted odds of women with more autonomy are significantly 3.8 times more likely to complete at least 4 ANC services than those women with low autonomy.

\subsubsection{Adjusted odds ratio(AOR)}

After adjusting for several confounding factors, the odds of completing 4 ANC visits for women with 'more autonomy' dropped significantly from 3.79 times to I.24 times for women with 'low autonomy' (table 5). The odds of attending at least 4 ANC increased significantly as the age in group, educational level, and wealth status increased.

\section{Dicussion}

\section{I Discussion}

We applied factor analysis to construct theAutonomy Index (Al) for the respondents using the principal component factor option. We used the scores (expressed in 10 scales) for the three dimensions of women decision making autonomy (deciding on their own health care; making major household purchases, and visits to family or relatives) as collected in 2013 NDHS. These variables were further converted into dichotomous variables of ' 0 ' \& ' $I$ ', where 'I' means having the item and ' 0 ' not having it. 
Table 2: Social demographic characteristics of study participants

\begin{tabular}{|c|c|c|}
\hline Variables & Number & Percentage \\
\hline \multicolumn{3}{|l|}{ ANC visit status } \\
\hline Did not meet WHO standard $(<4)$ & 9,464 & 47.5 \\
\hline Met WHO standard (>3) & 10,457 & 52.5 \\
\hline \multicolumn{3}{|l|}{ Level of autonomy } \\
\hline Low autonomy & 16,568 & 59.53 \\
\hline More autonomy & 11,262 & 40.47 \\
\hline \multicolumn{3}{|l|}{ Age at first marriage } \\
\hline $15-24$ years & 26,762 & 90.4 \\
\hline $25-34$ years & 2,728 & 9.2 \\
\hline 35 years + & 130 & 0.4 \\
\hline \multicolumn{3}{|l|}{ Number of living children } \\
\hline 0 & $\mathrm{II}, 750$ & 30.2 \\
\hline $\mathrm{I}-2$ & 9,737 & 25.0 \\
\hline $3-4$ & 8,876 & 22.8 \\
\hline $5+$ & 8,584 & 22.0 \\
\hline \multicolumn{3}{|l|}{ Union or marital status } \\
\hline Never in union & 9,325 & 23.9 \\
\hline Currently in union & 2,7830 & 71.5 \\
\hline Formerly in union & $\mathrm{I}, 793$ & 4.6 \\
\hline \multicolumn{3}{|l|}{ Total children ever born } \\
\hline $0-4$ children & 27541 & 70.7 \\
\hline $5+$ children & 11,406 & 29.3 \\
\hline \multicolumn{3}{|l|}{ Region } \\
\hline North central & 5572 & 14.3 \\
\hline North east & 5766 & 14.8 \\
\hline North west & 11876 & 30.5 \\
\hline South east & 4476 & 11.5 \\
\hline South South & 4942 & 12.7 \\
\hline South west & 6314 & 16.2 \\
\hline \multicolumn{3}{|l|}{ Place of residence } \\
\hline Urban & 16414 & 42.1 \\
\hline Rural & 22533 & 57.9 \\
\hline \multicolumn{3}{|l|}{ Level of education } \\
\hline No education & 14723 & 37.8 \\
\hline Primary education & 6733 & 17.3 \\
\hline Secondary+ & 17485 & 11.9 \\
\hline \multicolumn{3}{|l|}{ Age in group } \\
\hline $15-24$ years & 14576 & 37.4 \\
\hline $25-34$ years & 12611 & 32.4 \\
\hline 35 yearst & 11760 & 30.2 \\
\hline
\end{tabular}

Table 3: Relationship between participant's characteristics and ANC visit

\begin{tabular}{|c|c|c|c|}
\hline \multirow[t]{2}{*}{ Variables } & \multicolumn{2}{|c|}{ ANC Visits } & \multirow{2}{*}{$\begin{array}{c}\text { Chi-Square } \\
\text { (P-Value) }\end{array}$} \\
\hline & $\begin{array}{c}\text { Less } \\
\text { than } 4\end{array}$ & $\begin{array}{c}\text { More } \\
\text { than } 3\end{array}$ & \\
\hline \multicolumn{4}{|l|}{ Level of autonomy } \\
\hline Low autonomy & 7,084 & 4,704 & 1744.67 \\
\hline More autonomy & 2,019 & 5,085 & $(0.000) * * *$ \\
\hline \multicolumn{4}{|l|}{ Wealth status } \\
\hline Poor & 8281 & 4693 & 3919.67 \\
\hline Not poor & 1183 & 5764 & $(0.000) * * *$ \\
\hline \multicolumn{4}{|l|}{ Age at first marriage } \\
\hline I5-24 years & 9071 & 8782 & 717.79 \\
\hline $25-34$ years & 2523 & 1333 & $(0.000) * * *$ \\
\hline 35 years + & 6 & 38 & \\
\hline \multicolumn{4}{|c|}{ Total children ever born } \\
\hline 0-4 Children & 5393 & 7064 & 3394 \\
\hline 5+Children & 4071 & 3394 & $(0.000) * * *$ \\
\hline \multicolumn{4}{|l|}{ Place of residence } \\
\hline Urban & 1567 & 5420 & 2677.92 \\
\hline Rural & 7897 & 5037 & $(0.000) * * *$ \\
\hline \multicolumn{4}{|l|}{ Level of education } \\
\hline No education & 6963 & 2699 & $487 I .34$ \\
\hline Primary education & $14 \mid 4$ & 2381 & $(0.000) * * *$ \\
\hline Secondary+ & 1088 & 5377 & \\
\hline \multicolumn{4}{|l|}{ Age in group } \\
\hline 15-24 years & 2854 & 2376 & 142.54 \\
\hline $25-34$ years & 4163 & 5194 & $(0.000)^{* * *}$ \\
\hline 35 yearst & 2448 & 2887 & \\
\hline
\end{tabular}

Table 4: Logistic regression analysis for ANC Visits and autonomy status

\begin{tabular}{llll}
\hline \multicolumn{1}{c}{ Variables } & UOR & CI & P-Value \\
\hline Autonomy status & & & \\
\hline Low autonomy & 1.000 & & \\
\hline More autonomy & 3.792 & $(3.394 .24)$ & $0.000 * * *$ \\
\hline
\end{tabular}

The kmo of 0.736 measures the adequacy of sample-size of women decision making autonomy indicating that a higher correlation existed between different decision making autonomy statuses to warrant using factor analysis. ${ }^{20}$ The finding that only about $40 \%$ Nigerian women has autonomy in 
Table 5: Logistic regression analysis for ANC Visits and autonomy status (Adjusted odds ratio)

\begin{tabular}{|c|c|c|c|}
\hline & $\begin{array}{l}\text { Odds } \\
\text { ratio }\end{array}$ & Cl & P-Value \\
\hline \multicolumn{4}{|l|}{ Autonomy level } \\
\hline Low autonomy & 1.000 & & \\
\hline More autonomy & 1.240 & $(1.1011 .396)$ & $0.000 * * *$ \\
\hline \multicolumn{4}{|l|}{ Age in group } \\
\hline I5-24 years & 1.000 & & \\
\hline $25-34$ years & 1.151 & $(0.0101 .311)$ & $0.035^{*}$ \\
\hline $35+$ years & 1.282 & $(1.08 \mid 1.522)$ & $0.004 * * *$ \\
\hline \multicolumn{4}{|l|}{ Education level } \\
\hline No education & 1.000 & & \\
\hline Primary education & 1.935 & (I.662 2.242) & $0.000 * * *$ \\
\hline Secondary+ & 2.959 & $(2.4973 .506)$ & $0.000 * * *$ \\
\hline \multicolumn{4}{|l|}{ Place of residence } \\
\hline Urban & 1.000 & & \\
\hline Rural & 0.818 & $(0.68 \mid 0.982)$ & $0.032 *$ \\
\hline \multicolumn{4}{|l|}{ Wealth status } \\
\hline Poorest & 1.000 & & \\
\hline Poor & 1.892 & (I.564 2.289) & $0.000 * * *$ \\
\hline Middle & 3.416 & $(2.7434 .253)$ & $0.000 * * *$ \\
\hline Richer & 5.072 & $(3.96 \mid 6.492)$ & $0.000 * * *$ \\
\hline Richest & 8.260 & $(6.19411 .016)$ & $0.000 * * *$ \\
\hline \multicolumn{4}{|l|}{ Region } \\
\hline North central & 1.000 & & \\
\hline North east & 0.978 & $(0.759$ I.266) & $0.876(\mathrm{NS})$ \\
\hline North west & 0.649 & $(0.5100 .825)$ & $0.000 * * *$ \\
\hline South south & 2.598 & $(1.9173 .521)$ & $0.000 * * *$ \\
\hline South west & 0.688 & $(0.5370 .88 I)$ & $0.003^{* * *}$ \\
\hline South east & 2.856 & $(1.89 \mid 4.313)$ & $0.000 * * *$ \\
\hline \multicolumn{4}{|l|}{ Children ever born } \\
\hline 0 & 1.000 & & \\
\hline $\mathrm{I}-2$ & 1.031 & $(0.890$ I.195) & 0.685 (NS) \\
\hline $3-4$ & 0.963 & $(0.857$ I.082) & 0.523 (NS) \\
\hline $5+$ & 1.000 & & \\
\hline \multicolumn{4}{|l|}{ Age at $I^{\text {st }}$ marriage } \\
\hline I5-24 years & 1.000 & & \\
\hline $25-34$ years & 1.238 & $(1.026$ I.494) & $0.026^{*}$ \\
\hline $35+$ years & 2.196 & $(0.7516 .418)$ & 0.150 (NS) \\
\hline
\end{tabular}

deciding on issues that pertain to her health, large purchases for family and visit outside the home either singly or jointly with her husband is relatively low. Furthermore, the principal exposure variable, women autonomy was found to be significantly associated with ANC utilization in Nigeria. This agrees with similar studies in Nigeria ${ }^{12,13}$ and in some Asian countries, ${ }^{8,9}$ using different analytical approaches,but the result was at variance with other findings in Nepal. ${ }^{10}$ The significance of women autonomy as a risk factor for ANC utilization even after adjusting for other confounding factors makes it very relevant especially in resource limited settings like Nigeria.

\subsection{Limitations}

However, the interpretations of the results from this study are subject to a number of limitations. First, the study is cross sectional and as such causal effects could not be determined. Second, the study did not examine the independent predictor effects of other significant independent variables. Third, in view of the multi ethnic diversities of Nigeria, cultural impediments to ANC were not examined. Fourth, the constituents of women decision status as collected by NDHS were in 3 dimensions. These could have been more to further justify the use of factor analysis. Overall, the strength of the results from the study draws upon the nationally representativeness of the large sample size of the NDHS. Future studies should identify more research gap in the areas of identifying cultural impediments in the use of ANC in Nigeria. For example, interactions of both maternal and paternal variables can be investigated and how much both household and paternal variables can explain the relationships between maternal characteristics and ANC.

\section{Conclusion and Global Health Implications}

This study used factor analysis to construct autonomy index for women in Nigeria and have demonstrated that it is as good as any other analytical methods. ${ }^{15}$ Women autonomy is undoubtedly a major determinant of ANC utilization in Nigeria. The result further demonstrated that the usage of ANC increases as age of respondents, education status, wealth index and age at $\mathrm{I}^{\text {st }}$ marriage increase. In view of the above, it suggest the need for the implementations of policies and programs that will enhance women autonomy status in the following 
areas: (I) women empowerment programs that will increase their income generating power especially the rural women, (2) encouraging parents to educate their girl-child rather than forcing them into early child marriage, (3) increasing the focus of men to be more responsive in their wives needs to access ANC during pregnancy and postpartum periods. This is important because paternal attitude has been found to be an important factor that influences many women in seeking quality care, ${ }^{21}$ and (4) increasing access to quality ANC centers especially in the rural areas.

\section{Compliance with ethical standards}

Conflicts of Interest: The authors declared no conflicts of interest relevant to this study. Funding/Support: The authors declared that no funding was received to carry out this research. Acknowledgement: We deeply acknowledge Measure DHS and National Population Commission for the permission granted us to use the data for this study. Ethics Approval: Ethical permission to use the data for this study was obtained from Opinion Research Corporation (ORC) Macro International, Incorporated, Calverton, USA; the Nigeria Demographic and Health survey (NDHS) was approved by Ethics Committee of ORC Macro Inc. and by the National Ethics Committee of Federal Ministry of Health, Nigeria.

\section{Key Messages}

- The prevalence of Antenatal Care (ANC) visits of minimum 4 times during pregnancy among Nigerian women was slightly above 52 percent.

- For women in Nigeria, decision making autonomy is a major determinant of ANC utilization.

- The usage of ANC among Nigerian women increases as their ages increase.

\section{References}

I. World Health Organization. Maternal mortalityFactsheets http://www.who.int/en/news-room/factsheets/detail/maternal-mortality accessed May I, 2018

2. World Health Organization. Trends in Maternal Mortality, 1990 to 2008 Estimates. WHO, UNICEF, UNFPA and The World Bank. Geneva:World Health Organization; 2010

3. Alkema L, Chou D, Hogan D, Zhang S, Moller AB,
Gemmill A, et al. Global, regional, and national levels and trends in maternal mortality between 1990 and 2015, with scenario-based projections to 2030: a systematic analysis by the UN Maternal Mortality Estimation Inter-Agency Group. Lancet. 2016; 387 (100|7):462-74.

4. Fagbamigbe AF \& Idemudia ES. Barriers to Antenatal Care use in Nigeria: Evidences from Non-Users and Implications for Maternal Health Programming. BMC Pregnancy and Childbirth 2015, 15:95

5. Nisar N, White F. Factors affecting utilization of Antenatal Care among reproductive age group Women (15-49 years) in an urban squatter settlement of Karachi, Journal of Pakistan Medical Association,2003 Feb; 53(2):47-53.

6. World Statistics 2015. WHO Library Cataloguing-inPublication Data, http://apps.who.int/iris/bitstream/ handle/I0665/I 70250/9789240694439_eng. pdf? sequence=I accessed May I, 2018.

7. National Population Commission and ICF Macro. Nigeria Demographic and Health Survey 20 I3.Abuja, Nigeria: National Population Commission and ICF Macro, 2014

8. Beegle, K., Frankenberg, E. \& Thomas, D. Bargaining Power within Couples and use of Prenatal and Delivery Care in Indonesia. Stud Fam Plann, 200I, 32, 130-46.

9. Balk, D. Individual and Community Aspects of Women's Status and Fertility in Rural Bangladesh. Population Studies, 1994, 48(I): 2 I-45.

10. Furuta M \& Salway S. Women's Position within the Household as a Determinant of Maternal Health Care Use in Nepal. Int Fam Plan Perspect. 2006 Mar; 32(I):17-27.

II. Deo KK, PaudelYR, Khatri RB, Bhaskar RK, Paudel R, Mehata $S$ and Wagle RR. Barriers to Utilization of Antenatal Care Services in Eastern Nepal, Front Public Health. 2015; 3: 197. doi: 10.3389/fpubh.2015.00197

12. Fapohunda BM, Orobaton NG.When Women Deliver with No One Present in Nigeria:Who, What, Where and So What? July 25, 2013. https://doi.org//0.137I/ journal.pone.0069569 accessed May I, 2018.

13. Sadiq AM The Use of Maternal Health Services in Nigeria: Does Ethnicity and Religious Beliefs Matter? MOJ Public Health, 2017; 6(6).

14. Tiruneh FN, Chuang K and Chuang Y. Women's autonomy and maternal healthcare service 
utilization in Ethiopia BMC Health Service Research, 2017 17:7|8. DOI 10.|186/s |29|3-017-2670-9

15. Bamiwuye SO De Wet $N$ Adedini SA Linkages between Autonomy, Poverty and Contraceptive Use in Two sub-Saharan African Countries. African Population Studies. 27(2), October 2013

16. Slinkard SA, Pharr JR, Bruno T, Patel D, Ogidi A Obiefune M, Ezeanolue EE. Determinants of Infant Mortality in Southeast Nigeria: Results from the Healthy Beginning Initiative, 20I3-20l4. Int J MCH AIDS, 2018; 7(I); I - 8

17. World Health Organization.WHO recommendations on antenatal care for a positive pregnancy experience. c2016. http://www.who.int/reproductivehealth/ publications/maternal_perinatal_health/anc-positivepregnancy-experience/en accessed July 19, 2018.

18. Gabr HMKM. Investigating Poverty and Labour Force Participation among Older Population in
Egypt: Multilevel Simultaneous Equations Modeling Approach. A thesis submitted to The University of Birmingham for the degree of Ph.D in Statistics, School of Mathematics, The University of Birmingham, January 2016

19. StataCorporation, Stata Statistical Software, College Station, TX, 2014.

20. Venkaiah K, Brahmam GNV and Vijayaraghavan K. Application of Factor Analysis to Identify Dietary Patterns and Use of Factor Scores to Study Their Relationship with Nutritional Status of Adult Rural Populations. Journal of Health and Population Nutrition $2011 ; 29(4): 327-338$

21. Amutah-Onukagha N, Rodriguez M, Opara I, Gardner M,Assan MA, Hammond R, Plata J, Pierre K, Farag E. Progresses and challenges of utilizing traditional birth attendants in maternal and child health in Nigeria. Int J MCH AIDS, 20 I 7, 6(2) I 30-I 38 